\title{
The precompetition macronutrient intake of elite gaelic football players
}

\author{
Cathal Cassidy \\ Technological University Dublin, cathalncassidy@gmail.com \\ Kieran Collins \\ Technological University Dublin, kieran.collins@tudublin.ie \\ Marcus Shortall \\ Technological University Dublin, marcus.shortall@tudublin.ie
}

Follow this and additional works at: https://arrow.tudublin.ie/ittsciart

Part of the Sports Sciences Commons

\section{Recommended Citation}

Cassidy C, Collins K, Shortall M. The Precompetition Macronutrient Intake of Elite Gaelic Football Players. Int J Sport Nutr Exerc Metab. 2018 Nov 1;28(6):574-579. doi: 10.1123/ijsnem.2017-0292. Epub 2018 Jun 12. PMID: 29405786.

This Article is brought to you for free and open access by the School of Science and Computing at ARROW@TU Dublin. It has been accepted for inclusion in Articles by an authorized administrator of ARROW@TU Dublin. For more information, please contact arrow.admin@tudublin.ie, aisling.coyne@tudublin.ie, gerard.connolly@tudublin.ie.

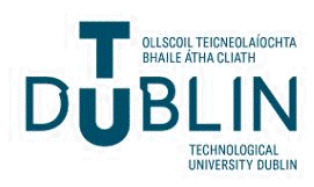


See discussions, stats, and author profiles for this publication at: https://www.researchgate.net/publication/322970177

\section{The Pre-Competition Macronutrient Intake of Elite Gaelic Football Players}

Article in International Journal of Sport Nutrition and Exercise Metabolism · February 2018

DOI: 10.1123/ijsnem.2017-0292

\section{CITATIONS}

10

3 authors, including:

Kieran Collins

Technological University Dublin - Tallaght Campus

129 PUBLICATIONS 1,863 CITATIONS

SEE PROFILE
READS

1,092

Some of the authors of this publication are also working on these related projects: 10 PUBLICATIONS 58 CITATIONS

SEE PROFILE

Project An analysis of contextual variables with respect to running performance in Inter County Gaelic football. View project

Elo Ratings System for Gaelic Football View project 
"The Pre-Competition Macronutrient Intake of Elite Gaelic Football Players" by Cassidy C, Collins K, Shortall M International Journal of Sport Nutrition and Exercise Metabolism

Note: This article will be published in a forthcoming issue of the International Journal of Sport Nutrition and Exercise Metabolism. This article appears here in its accepted, peerreviewed form; it has not been copyedited, proofed, or formatted by the publisher.

Section: Original Research

Article Title: The Pre-Competition Macronutrient Intake of Elite Gaelic Football Players

Authors: Cathal Cassidy ${ }^{1}$, Kieran Collins $^{1,2}$, and Marcus Shortall ${ }^{1,2}$

Affiliations: ${ }^{1}$ Department of Science, Institute of Technology Tallaght, Dublin, Ireland. ${ }^{2}$ Gaelic Sports Research Centre, Department of Science, Institute of Technology Tallaght, Dublin, Ireland.

Running Head: Pre-match nutrition in Gaelic football

Journal: International Journal of Sport Nutrition and Exercise

Acceptance Date: January 4, 2018

(C)2018 Human Kinetics, Inc.

DOI: https://doi.org/10.1123/ijsnem.2017-0292 
"The Pre-Competition Macronutrient Intake of Elite Gaelic Football Players" by Cassidy C, Collins K, Shortall M International Journal of Sport Nutrition and Exercise Metabolism

(C) 2018 Human Kinetics, Inc.

Category of Manuscript: Original Research

Title: The Pre-Competition Macronutrient Intake of Elite Gaelic Football Players

Authors: Cathal Cassidy ${ }^{[1]}$, Kieran Collins ${ }^{[1]}{ }^{[2]}$, Marcus Shortall ${ }^{[1]}{ }^{[2]}$

\title{
Affiliations:
}

${ }^{[1]}$ Department of Science, Institute of Technology Tallaght, Tallaght, Dublin 24, Ireland.

${ }^{[2]}$ Gaelic Sports Research Centre, Department of Science, Institute of Technology Tallaght, Tallaght, Dublin 24, Ireland.

Running Head: Pre-Match Nutrition in Gaelic Football

\author{
Corresponding Author: \\ Cathal Cassidy \\ Department of Science, \\ Institute of Technology Tallaght, \\ Tallaght, Dublin 24, Ireland. \\ Email: cathalncassidy@gmail.com
}


"The Pre-Competition Macronutrient Intake of Elite Gaelic Football Players" by Cassidy C, Collins K, Shortall M International Journal of Sport Nutrition and Exercise Metabolism

(C) 2018 Human Kinetics, Inc.

\section{ABSTRACT}

Competition related dietary intake has not yet been investigated in Gaelic football. The present study examined the pre-competition macronutrient intake of elite male Gaelic football players. Forty players from two teams completed a food diary on the two days preceding competition (DAY-1 \& DAY-2) and on match date pre-match (MATCH-DAY). Carbohydrate intake was significantly greater on DAY-2 compared to DAY-1, for both absolute [295 \pm 98 vs. $318 \pm 77 \mathrm{~g}](\mathrm{p}=0.048 ;-23.6 \mathrm{~g}$ [-47.3 to 0.2]; Cohen's $d=0.27)$ and relative intake $\left[3.4 \pm 1.1\right.$ vs. $3.7 \pm 1.0$ g.kg $\left.{ }^{-1}\right]\left(p=0.027 ;-0.3 g^{\prime} \cdot \mathrm{kg}^{-1}[-0.6\right.$ to -0.03$]$; Cohen's $d=0.32$ ). The number of players in accordance with and not in accordance with the guidelines for carbohydrate intake on DAY-2 was significantly different to an expected frequency distribution [ $\chi^{2}$ $(1)=32.400 ; p=\langle 0.001 ; \varphi=0.9]$ with a greater number of players not meeting the guidelines [observed $\mathrm{N}=2$ vs. 38]. The number of players in accordance with and not in accordance with the recommendations for carbohydrate intake on MATCH-DAY was significantly different to an expected frequency distribution $\left[\chi^{2}(1)=8.100 ; p=0.004 ; \varphi=0.45\right]$ with a greater number of players meeting the guidelines [observed $N=29$ vs. 11]. The major finding from the current investigation was that a significantly greater number of players did not meet carbohydrate intake guidelines on the day before competition. Individualised nutritional interventions are required in order to modify current prematch dietary intake.

Keywords: carbohydrate, glycogen, pre-match. 
"The Pre-Competition Macronutrient Intake of Elite Gaelic Football Players" by Cassidy C, Collins K, Shortall M International Journal of Sport Nutrition and Exercise Metabolism

(C) 2018 Human Kinetics, Inc.

\section{INTRODUCTION}

Gaelic football is a team-based invasion field sport indigenous to Ireland (Reilly et al., 2015). It represents the most popular of the Gaelic games governed by the Gaelic Athletic Association (GAA) (Beasley, 2015). The elite Gaelic football season consists of competitions played between January and September of each calendar year, with the major competitions being the national leagues, the provincial championships and the All-Ireland championship (Malone et al., 2016). Despite its amateur status, the commitment of players, the dedication of coaches and the standard of competition is analogous to that of professional sport (Reilly \& Doran, 2001). Furthermore, the popularity of elite Gaelic football is reflected in the tens of thousands of spectators that regularly attend fixtures (Reilly \& Collins, 2008).

Senior elite Gaelic football matches are played over seventy minutes, consisting of two halves of thirty-five minutes in duration (Davies et al., 2016). Players have been reported to expend 58-70 kJ.kg ${ }^{-1}$ body mass per match depending on the positional role (Malone et al., 2017a). Match-play involves intermittent high-intensity movements interspersed with periods of moderate and low intensity activity (Collins et al., 2013). The high-intensity bouts of activity have been described as being stochastic and unstable in nature (Malone et al., 2017b). The major fuel utilised by skeletal muscle during high-intensity exercise is glycogen contained within the muscle (Balsom et al., 1999a). It has been determined that intermittent high-intensity exercise performance is enhanced by a high muscle glycogen availability (Bangsbo et al., 1992; Balsom et al., 1999b; Skein et al., 2012). Considering the activity profile of Gaelic football, it is likely that intramuscular glycogen stores contribute significantly to energy production (Beasley, 2015). A high dietary carbohydrate intake can increase muscle glycogen stores within 24 hours (Bussau et al., 2002). Accordingly, current pre-competition nutritional guidelines recommend $7 \mathrm{~g} \cdot \mathrm{kg}^{-1}$ of carbohydrate to be consumed on the day before competition (Burke et al., 2011; Thomas et al., 2016). Furthermore, adequate carbohydrate intake on the day of competition is required with current guidelines recommending 1-4 g. $\mathrm{kg}^{-1}$ consumed 1-4 hours prior to the game (Burke et al., 2011; Thomas et al., 2016). It is generally advised to reduce fat intake in the 
"The Pre-Competition Macronutrient Intake of Elite Gaelic Football Players" by Cassidy C, Collins K, Shortall M International Journal of Sport Nutrition and Exercise Metabolism

(C) 2018 Human Kinetics, Inc.

pre-competition period in favour of increased carbohydrate consumption whilst moderate intakes of dietary protein are recommended (Thomas et al., 2016).

In recent decades there has been an emergence and growth of scientific research in Gaelic football however little attention has been paid to the nutritional status and requirements of elite players (Beasley, 2015). The limited number of studies that have assessed dietary intake have examined the general training diet (Collins et al., 2011; Reeves \& Collins, 2003). This research has identified that the players carbohydrate intake across a seven day period was not in accordance with the athletic guidelines of the time (Reeves \& Collins, 2003). Furthermore, it has been reported that the macronutrient percentage of energy intake in elite players was not of an optimal proportion for an athletic population, with players consuming excess fat and insufficient carbohydrate (Collins et al., 2011). It appears that further research is required in order to determine whether the nutritional intakes of players follow a similar pattern in the pre-competition period. Additionally, other team sports such as soccer, Australian football, rugby league and rugby union have all reported that players were not consuming adequate carbohydrate on the day prior to competition which indicates that this has been an issue of concern within team sport nutrition (Anderson et al., 2017; Bradley et al., 2015; Lundy et al., 2006; Schokman et al., 1999).

Therefore the aims of the current study were to examine the macronutrient intake of elite male Gaelic football players on the two days preceding competition (DAY-1 and DAY-2) and on the match-day prior to the game (MATCH-DAY) in order to determine whether there was a difference between: (1) carbohydrate intake on DAY-1 and DAY-2; (2) the number of players in accordance with and not in accordance with the guidelines for carbohydrate intake on DAY-2 and (3) the number of players in accordance with and not in accordance with the recommendations for carbohydrate intake on MATCH-DAY. It was hypothesised that: (1) carbohydrate intake would be significantly greater on DAY-2; (2) a significantly greater number of players would not meet the guidelines for carbohydrate intake on DAY-2 despite increasing their carbohydrate intake from DAY-1 and (3) a significantly greater 
"The Pre-Competition Macronutrient Intake of Elite Gaelic Football Players" by Cassidy C, Collins K, Shortall M International Journal of Sport Nutrition and Exercise Metabolism

(C) 2018 Human Kinetics, Inc.

number of players would not meet the minimum recommendations for carbohydrate intake on MATCH-DAY.

METHODS

\section{Participants}

Forty elite male Gaelic football players (age: $24.6 \pm 2.9$ years, height: $183.4 \pm 7.1 \mathrm{~cm}$, body mass: $84.3 \pm 7.9 \mathrm{~kg}$ ) from two senior Gaelic football squads were recruited to participate in the study. All participants were free of injury, illness and suspension at the time of data collection and therefore available for selection for competitive match-play. The participants were provided with information explaining the nature and purposes of the research and gave their informed consent. Ethical approval was granted by the research ethics committee of the local institution. The study was conducted according to the World Medical Association (WMA) Declaration of Helsinki (2013) for research involving human participants.

\section{Experimental Design}

Data collection procedures took place in January 2017 at the beginning of the elite Gaelic football season and after a pre-season training block. The participants were required to complete a food diary on the two days preceding competition (DAY-1 \& DAY-2) and on the match-day prior to the game (MATCH-DAY). DAY-1 was utilised as a comparison day whereby macronutrient intake on DAY1 was compared to DAY- 2 in order to determine whether the players had modified their nutritional intake in preparation for competition. The MATCH-DAY consisted of the recording of dietary intake prior to the game but did not require participants to record intake during or post-competition. Two Bord Na Móna O'Byrne Cup group-stage fixtures were used in the current study with the games for both of the participating teams commencing at 14:00 hours. The O'Byrne Cup is a provincial competition organised by the Leinster GAA at the beginning of each calendar year and precedes the major inter-county competitions. 
"The Pre-Competition Macronutrient Intake of Elite Gaelic Football Players" by Cassidy C, Collins K, Shortall M International Journal of Sport Nutrition and Exercise Metabolism

(C) 2018 Human Kinetics, Inc.

\section{Experimental Procedures}

\section{Dietary Records}

Paper-based food diaries were distributed to each participant by the team performance nutritionist along with instruction hand-outs detailing how to accurately record nutritional intake. The players were asked to complete a hand-written recording of all the foods and fluids they consumed. They were instructed to make note of the time of consumption, the type and quantity of food/drink, the brand name, the ingredients contained within homemade preparations and also the method of cooking. It was advised that the participants recorded their dietary intake close to the time of ingestion in order to maintain accuracy. Team staff did not prepare or organise any meals for the players. Following completion of the dietary record, the food diaries were returned to the performance nutritionist. The food diaries were subsequently collected and each individual dietary record was examined for points of ambiguity and inaccuracy. Current age, stature and body mass information was also provided by the team performance nutritionist.

\section{Quantification of Dietary Intake}

Dietary intake was analysed using professional nutrition analysis software (Nutritics v4.312, Nutritics Ltd., Swords, Co. Dublin, Ireland). Records for DAY-1, DAY-2 and MATCH-DAY were inputted into the software, with all relevant nutritional information in the food diary included. Energy and macronutrient intakes were quantified and recorded as both absolute values and values relative to per kilogram of body mass. Macronutrient intakes were also expressed as a percentage of energy intake. For MATCH-DAY, considering the 2 p.m. throw-in time, carbohydrate intake between the period of 10 a.m. - 1 p.m. was quantified in order to assess whether each player met the guidelines (1 - 4 g. $\mathrm{kg}^{-1}$ consumed 1 - 4 hours before competition). Energy, fat and protein intake on MATCH-DAY was also calculated for the same 3 hour period in order to align with carbohydrate quantification. 
"The Pre-Competition Macronutrient Intake of Elite Gaelic Football Players" by Cassidy C, Collins K, Shortall M International Journal of Sport Nutrition and Exercise Metabolism

(C) 2018 Human Kinetics, Inc.

\section{Misreporting of Energy Intake}

In order to identify under- or over-reporting of energy intake, the ratio of energy intake to basal metabolic rate (El:BMR) was calculated at the group-level (Black, 2000; Goldberg et al., 1991). Mean energy intake from DAY-1 and DAY-2 and mean BMR were utilised for the ratio calculation. BMR was estimated using the Harris-Benedict equation (Harris \& Benedict, 1918). The Harris-Benedict equation is the recommended predictive equation for BMR in athletic populations when fat free mass or lean body mass are unknown (Burke \& Deakin, 2015). A physical activity level (PAL) of 1.45 was selected based on knowledge of the current population. Lower and upper $95 \%$ confidence limits were calculated from the updated equations provided by Black (2000).

\section{Statistical Analysis}

Data is presented as mean \pm standard deviation (SD). All statistical analysis procedures were conducted using IBM SPSS statistical software (v23.0 for windows, IBM corporation, Armonk, New York, United States). Paired-sample t-tests were used to determine whether there was a significant difference in carbohydrate intake between DAY-1 and DAY-2. Parametric assumptions for the paired t-tests were established for all variables by means of the observation of box-plots for the removal of outliers and Shapiro-Wilk tests for normal distribution of data $(p>0.05)$.

Chi-square goodness-of-fit tests were conducted to determine whether the number of players in accordance with the guidelines and the number of players not in accordance with the guidelines for carbohydrate intake on both DAY-2 and MATCH-DAY were significantly different to an expected frequency distribution. Each of the 40 participants were classified into one of two groups of the categorical variable: 1 = player in accordance with the guidelines; 2 = player not in accordance with the guidelines. The expected frequency was equally distributed between each group of the categorical variable (expected $\mathrm{N}=20$ ). Non-parametric assumptions for chi-square goodness-of-fit tests were established by the presence of one low-level data variable, by the confirmation of independence of observations and by verification that $80 \%$ of the expected frequencies in each group were $\geq 5$. 
"The Pre-Competition Macronutrient Intake of Elite Gaelic Football Players" by Cassidy C, Collins K, Shortall M International Journal of Sport Nutrition and Exercise Metabolism

(C) 2018 Human Kinetics, Inc.

Statistical significance was established as $\alpha<0.05$ for both the paired t-tests and the chi-square goodness-of-fit tests. Cohen's $d$ was used an effect size statistic for the paired t-tests $(0.2=$ small; 0.5 $=$ medium; $0.8=$ large) while the Phi coefficient $(\varphi)$ was utilised as a measure of effect size for chisquare goodness-of-fit tests (0.1 = small; $0.3=$ medium; $0.5=$ large) (Cohen, 1988).

\section{RESULTS}

\section{Energy and Macronutrient Intake}

The mean \pm SD for energy and macronutrient intake on DAY-1, DAY-2 and MATCH-DAY (prematch: 10 a.m. - 1 p.m.) are presented in Table 1. Absolute macronutrient intakes are reported in grams (g). Relative macronutrient intakes consist of grams per kilogram of body mass $\left(\mathrm{g} \cdot \mathrm{kg}^{-1}\right)$. Results for the paired t-tests are reported as ( $p$-value; mean difference [ $95 \% \mathrm{Cl}$ of the mean difference]; effect size). Carbohydrate intake was significantly greater on DAY-2 compared to DAY-1, for both absolute $(p=0.048 ;-23.6$ g $[-47.3$ to 0.2$] ;$ Cohen's $d=0.27)$ and relative carbohydrate intake $(p=0.027 ;-0.3$ g.kg ${ }^{-1}[-0.6$ to -0.03$]$; Cohen's $d=0.32$.

\section{Carbohydrate Intake and Pre-Competition Guidelines}

Current guidelines for carbohydrate intake can be viewed in Table 2. Results for chi-square goodness-of-fit tests are reported as [observed $\mathrm{N}$ ] and [chi-square value $\left(\mathrm{\chi}^{2}\right)$; degrees of freedom (df); p-value; effect size $(\varphi)]$. Of the 40 participants recruited to the study, the number of players in accordance with the guidelines [observed $\mathrm{N}=2$ ] and not in accordance with the guidelines [observed $\mathrm{N}=38$ ] for relative carbohydrate intake on DAY-2 was significantly different to an expected frequency distribution $\left[\chi^{2}=32.400 ; \mathrm{df}=1 ; \mathrm{p}=\langle 0.001 ; \varphi=0.9]\right.$ with a greater number of players not meeting the guidelines (Figure 1). The number of players in accordance with the guidelines [observed $N=29$ ] and not in accordance with the guidelines [observed $\mathrm{N}=11$ ] for relative carbohydrate intake on MATCHDAY was significantly different to an expected frequency distribution $\left[\chi^{2}=8.100 ; d f=1 ; p=0.004 ; \varphi=\right.$ 0.45] with a greater number of players meeting the guidelines (Figure 2). 
"The Pre-Competition Macronutrient Intake of Elite Gaelic Football Players" by Cassidy C, Collins K, Shortall M International Journal of Sport Nutrition and Exercise Metabolism

(C) 2018 Human Kinetics, Inc.

\section{El:BMR Ratio}

Mean energy intake for DAY-1 and DAY-2 was $2872 \pm 480 \mathrm{kcal}$ and mean BMR equalled 1963 $\pm 114 \mathrm{kcal}$. The El:BMR ratio was calculated to be 1.46 with lower and upper $95 \%$ confidence limits of 1.42 to 1.48 .

\section{DISCUSSION}

The purpose of the current study was to examine the macronutrient intake of elite Gaelic football players on the two days preceding competition and on the match-day prior to the game. In relation to the first study aim, carbohydrate intake was significantly greater on DAY-2 compared to DAY-1 which supports the study hypothesis. With regards to the second study aim, the number of players in accordance with and not in accordance with the guidelines for carbohydrate intake on DAY2 was significantly different, with a greater number of players not in accordance with the guidelines which supports the study hypothesis. This indicates that despite a significant increase in carbohydrate intake on the day before competition, a significantly greater number of players were not consuming carbohydrate in line with the guidelines of $7 \mathrm{~g}^{\mathrm{kg}} \mathrm{g}^{-1}$ (Burke et al., 2011; Thomas et al., 2016).

It has been previously identified that elite Gaelic football players were not consuming adequate carbohydrate in their training diet (Collins et al., 2011; Reeves \& Collins, 2003). The results obtained in the current study suggest that this insufficient intake of carbohydrate is also present in the pre-competition period. These results are also consistent with the findings of other team sports such as soccer, rugby league, rugby union and Australian football (Anderson et al., 2017; Bradley et al., 2015; Lundy et al., 2006; Schokman et al., 1999). The inadequate intake of carbohydrate on the day preceding the game will likely result in sub-optimal muscle glycogen concentrations (Burke et al., 2011). Low glycogen levels may have a detrimental effect on the ability of the players to fulfil the physical and physiological demands of match-play considering that glycogen is the main energy substrate utilised by skeletal muscle during periods of high-intensity activity (Balsom, et al., 1999b; Williams \& Rollo, 2015). Running performance in particular may be compromised and such nutritional 
"The Pre-Competition Macronutrient Intake of Elite Gaelic Football Players" by Cassidy C, Collins K, Shortall M International Journal of Sport Nutrition and Exercise Metabolism

(C) 2018 Human Kinetics, Inc.

intakes may well be a contributing factor to the reported decrements in variables such as total distances, high-speed running distances and sprint distances covered across match-play (Malone et al., 2016; Ryan et al., 2017).

In relation to the third study aim, the number of players meeting and not meeting the recommendations for carbohydrate intake on MATCH-DAY was significantly different, with a greater number of players in accordance with the guidelines, which rejects the study hypothesis. It appears that most players had little difficulty meeting the 1-4 g. $\mathrm{kg}^{-1}$ guidelines before the match (Burke et al., 2011; Thomas et al., 2016). This perhaps indicates a perception among players in the present study that carbohydrate intake on the match-day alone is sufficient to maximise performance, with such intakes on the day before competition neglected. Carbohydrate intake on the day of competition can continue to increase muscle glycogen stores and is important for replenishing hepatic glycogen depots depleted by the overnight fast (Thomas et al., 2016). Blood glucose represents a key fuel for the central nervous system and a shortage of such fuel substrates can impair concentration, decision-making and skill execution whilst increasing perceptions of fatigue (Welsh et al., 2002).

The over-consumption of fat and protein in the pre-competition period appears to be an issue of concern. Guidelines for athletic populations recommend that fat should constitute approximately $20-35 \%$ of daily energy intake (Thomas et al., 2016). Chronic restriction of fat intake is not advised due the likelihood of developing deficiencies in fat soluble vitamins and essential fatty acids (Bishop et al., 1999). However, it is acceptable to acutely restrict fat to $<20 \%$ of energy intake in the pre-competition period in order to facilitate an increased consumption of carbohydrate (Thomas et al., 2016). Fat comprised $31 \%$ of the players' energy intake on DAY-2. Interpreting this value, it is evident that the players consumed excess fat and this may have hampered their carbohydrate intake. Likewise, fat intake on MATCH-DAY was rather high at $29 \%$ of energy intake. Elevated intakes of fat in close proximity to the match may increase the risk of gastrointestinal distress and can contribute to a delay in gastric emptying (De Oliveira et al., 2014; Jeukendrup, 2017). 
"The Pre-Competition Macronutrient Intake of Elite Gaelic Football Players" by Cassidy C, Collins K, Shortall M International Journal of Sport Nutrition and Exercise Metabolism

(C) 2018 Human Kinetics, Inc.

General protein intake guidelines for athletes recommend 1.2-2.0 g.kg-1 per day (Egan, 2016; Thomas et al., 2016). In the present study, protein intake was at the higher end of these guidelines. A high protein intake of close to $2.0 \mathrm{~g}^{\mathrm{kg}} \mathrm{kg}^{-1}$ appears to be more appropriate for when players are undertaking intense periods of training (Egan, 2016). Moderate protein intakes of 1.4-1.7 g. $\mathrm{kg}^{-1}$ have been recommended for intermittent team sport athletes and appear more suitable for typical pitchbased training and competition (Campbell et al., 2007). A high intake of dietary protein is associated with increased satiety and therefore the players in the current study may not have possessed the appetite to consume the necessary carbohydrate on the day before competition (Halton \& Hu, 2004). Overall, these findings are consistent with previous research that has identified that elite Gaelic games players were not obtaining energy in the optimum proportions (Collins et al., 2011). Energy intake on DAY-1 and DAY-2 was lower than values previously reported in elite Gaelic football players (Collins et al., 2011; Reeves \& Collins, 2003). The energy intake was also lower than recent findings in other team sports such as soccer and Australian football (Anderson et al., 2017; Devlin et al., 2017). However, it is the macronutrient percentage of this energy intake rather than total energy intake that is of concern in the current study. As a measure of the validity of reported energy intake, the El:BMR ratio obtained indicates that neither under-reporting nor over-reporting of energy intake is likely to have occurred in the present study (Black, 2000; Goldberg \& Black, 1998; McCrory et al., 2002).

A limitation of the current project was the number of participating teams and players. Perhaps a greater number of players recruited from a wider range of elite teams may provide a more conclusive representation of the population. The time-point of the season also needs to be taken into consideration. Dietary intake during a preliminary competition at the beginning of the season may be different to mid-season when the major competitions are underway. Accordingly, a similar investigation conducted at different time-points throughout the season is required. In addition, it must be acknowledged that nutritional recommendations for Gaelic football players are taken from general athletic guidelines which suggests the need for the development of sport-specific recommendations. 
"The Pre-Competition Macronutrient Intake of Elite Gaelic Football Players" by Cassidy C, Collins K, Shortall M International Journal of Sport Nutrition and Exercise Metabolism

(C) 2018 Human Kinetics, Inc.

In summary, the present investigation examined the pre-competition macronutrient intake of elite Gaelic football players. The major finding was that a significantly greater number of players were not in accordance with the guidelines for carbohydrate intake on the day before competition. Players consumed surplus fat and protein and a reduction of such intakes may facilitate a greater consumption of carbohydrate to support the demands of match-play. Carbohydrate consumed in line with the guidelines can optimise muscle glycogen stores which are the main energy substrate for periods of high-intensity activity. Competition focused nutritional strategies are required to ensure that players consume the appropriate quantity of macronutrients to maximise their performance.

\section{ACKNOWLEDGEMENTS}

The authors would like to thank all the players who participated in the study and also the team staff members who assisted in the data collection. A thank you to Dr. Joe Warne for his advice on the statistical analysis procedures.

\section{AUTHOR CONTRIBUTIONS}

CC conducted the dietary and statistical analysis and wrote the manuscript. $\mathrm{KC}$ reviewed and edited the manuscript. MS designed the study and was responsible for the distribution and collection of the food diaries. All authors approved the final version of the paper.

\section{DECLARATION OF FUNDING}

N/A

\section{CONFLICTS OF INTEREST}

N/A 
“The Pre-Competition Macronutrient Intake of Elite Gaelic Football Players" by Cassidy C, Collins K, Shortall M International Journal of Sport Nutrition and Exercise Metabolism

(C) 2018 Human Kinetics, Inc.

\section{REFERENCES}

Anderson, L., Orme, P., Naughton, R. J., Close, G. L., Milsom, J., Rydings, D., ... Morton, J. P. (2017). Energy intake and expenditure of professional soccer players of the English Premier League: evidence of carbohydrate periodization. International Journal of Sport Nutrition \& Exercise Metabolism, 27(3), 228-238.

Balsom, P. D., Gaitanos, G. C., Söderlund, K., \& Ekblom, B. (1999a). High-intensity exercise and muscle glycogen availability in humans. Acta Physiologica Scandinavica, 165(4), 337-345.

Balsom, P. D., Wood, K., Olsson, P., \& Ekblom, B. (1999b). Carbohydrate intake and multiple sprint sports: With special reference to football (soccer). International Journal of Sports Medicine, 20(1), 48-52.

Bangsbo, J., Norregaard, L., \& Thorsoe, F. (1992). The effect of carbohydrate diet on intermittent exercise performance. International Journal of Sports Medicine, 13(2), 152-157.

Beasley, K. J. (2015). Nutrition and Gaelic football: Review, recommendations, and future considerations. International Journal of Sport Nutrition and Exercise Metabolism, 25(1), 1-13.

Bishop, N. C., Blannin, A. K., Walsh, N. P., Robson, P. J., \& Gleeson, M. (1999). Nutritional aspects of immunosuppression in athletes. Sports Medicine, 28(3), 151-176.

Black, A. E. (2000). Critical evaluation of energy intake using the Goldberg cut-off for energy intake:basal metabolic rate. A practical guide to its calculation, use and limitations. International Journal of Obesity, 24(9), 1119-1130.

Bradley, W. J., Cavanagh, B., Douglas, W., Donovan, T. F., Twist, C., Morton, J. P., \& Close, G. L. (2015). Energy intake and expenditure assessed "in-season" in an elite European rugby union squad. European Journal of Sport Science, 15(6), 469-479.

Burke, L. M., \& Deakin, V. (2015). Clinical sports nutrition (5th ed.). McGraw Hill Education.

Burke, L. M., Hawley, J. A., Wong, S. H. S., \& Jeukendrup, A. E. (2011). Carbohydrates for training and competition. Journal of Sports Sciences, 29 (sup1), S17-27.

Bussau, V. A., Fairchild, T. J., Rao, A., Steele, P., \& Fournier, P. A. (2002). Carbohydrate loading in human muscle: An improved 1 day protocol. European Journal of Applied Physiology, 87(3), 290-295.

Campbell, B., Kreider, R. ., Ziengenfuss, T., La Bounty, P., Roberts, M., Burke, D., ... Antonio, J. (2007). International society of sports nutrition position stand: protein and exercise. Journal of International Society of Sports Nutrition, 4:8.

Cohen, J. (1988). Statistical power analysis for the behavioral sciences (2nd ed.). Lawrence Earlbaum Asssociates. Hillsdale, NJ.

Collins, K., Doran, D. A., \& Reilly, T. P. (2011). The energy intake of elite gaelic football players. In 7th World Congress on Science and Football, Nagoya, Japan.

Collins, K., Solan, B., \& Doran, D. (2013). A preliminary investigation into high-intensity activity during elite Gaelic football. Journal of Sports Therapy, 1:10. 
"The Pre-Competition Macronutrient Intake of Elite Gaelic Football Players" by Cassidy C, Collins K, Shortall M International Journal of Sport Nutrition and Exercise Metabolism

(C) 2018 Human Kinetics, Inc.

Davies, R. W., Toomey, C., McCormack, W., Hughes, K., Cremona, A., \& Jakeman, P. (2016). Body composition analysis of inter-county Gaelic athletic association players measured by dual energy X-ray absorptiometry. Journal of Sports Sciences, 34(11), 1015-1020.

De Oliveira, E. P., Burini, R. C., \& Jeukendrup, A. (2014). Gastrointestinal complaints during exercise: Prevalence, etiology, and nutritional recommendations. Sports Medicine, 44(1), 79-85.

Devlin, B., Leveritt, M., Kingsley, M., \& Belski, R. (2017). Dietary intake, body composition and nutrition knowledge of Australian football and soccer players: implications for sports nutrition professionals in practice. International Journal of Sport Nutrition and Exercise Metabolism, 27(2), 130-138.

Egan, B. (2016). Protein intake for athletes and active adults: Current concepts and controversies. Nutrition Bulletin, 41(3), 202-213.

Goldberg, G. R., \& Black, A. E. (1998). Assessment of the validity of reported energy intakes-review and recent developments. Food \& Nutrition Research, 42(1), 6-9.

Goldberg, G. R., Black, A. E., Jebb, S. A., Cole, T. J., Murgatroyd, P. R., Coward, W. A., \& Prentice, A. M. (1991). Critical evaluation of energy intake data using fundamental principles of energy physiology: 1 . Derivation of cut-off limits to identify under-recording. European Journal of Clinical Nutrition, 45(12), 569-581.

Halton, T., \& Hu, F. (2004). The effects of high protein diets on thermogenesis, satiety and weight loss: A critical review. Journal of the American College of Nutrition, 23(5), 373-385.

Harris, J. A., \& Benedict, F. G. (1918). A biometric study of human basal metabolism. Proceedings of the National Academy of Sciences, 4(12), 370-3.

Jeukendrup, A. E. (2017). Training the Gut for Athletes. Sports Medicine, 47(s1), 101-110.

Lundy, B., O'Connor, H., Pelly, F., \& Caterson, I. (2006). Anthropometric Characteristics and Competition Dietary Intakes of Professional Rugby League Players. International Journal of Sport Nutrition \& Exercise Metabolism, 16(2), 199-213.

Malone, S., Solan, B., \& Collins, K. (2017b). The running performance profile of elite gaelic football match-play. The Journal of Strength and Conditioning Research, 31(1), 30-36.

Malone, S., Solan, B., Collins, K., \& Doran, D. (2016). Positional Match Running Performance of Elite Gaelic Football. The Journal of Strength and Conditioning Research, 30(8), 2292-2298.

Malone, S., Solan, B., Collins, K., \& Doran, D. (2017a). The metabolic power and energetic demands of elite Gaelic football match play. The Journal of Sports Medince and Physical Fitness, 57(5), 543-549.

McCrory, M. A., McCrory, M. A., Hajduk, C. L., \& Roberts, S. B. (2002). Procedures for screening out inaccurate reports of dietary energy intake. Public Health Nutrition, 5(6A), 873-882.

Reeves, S., \& Collins, K. (2003). The nutritional and anthropometric status of gaelic football players. International Journal of Sport Nutrition and Exercise Metabolism, 13(4), 539-548.

Reilly, B., Akubat, I., Lyons, M., \& Collins, D. K. (2015). Match-play demands of elite youth Gaelic football using global positioning system tracking. The Journal of Strength and Conditioning Research, 29(4), 989-996. 
"The Pre-Competition Macronutrient Intake of Elite Gaelic Football Players" by Cassidy C, Collins K, Shortall M International Journal of Sport Nutrition and Exercise Metabolism

(C) 2018 Human Kinetics, Inc.

Reilly, T., \& Collins, K. (2008). Science and the Gaelic sports: Gaelic football and hurling. European Journal of Sport Science, 8(5), 231-240.

Reilly, T., \& Doran, D. (2001). Science and Gaelic football: a review. Journal of Sports Sciences, 19(3), 181-193.

Ryan, M., Malone, S., \& Collins, K. (2017). An Acceleration Profile of Elite Gaelic Football Match-Play. The Journal of Strength and Conditioning Research, Epub ahead of print.

Schokman, C. P., Rutishauser, I. H., \& Wallace, R. J. (1999). Pre- and postgame macronutrient intake of a group of elite Australian football players. International Journal of Sport Nutrition, 9(1), 60-69.

Skein, M., Duddfield, R., Kelly, B. T., \& Marino, F. E. (2012). The effects of carbohydrate intake and muscle glycogen content on self-paced intermittent-sprint exercise despite no knowledge of carbohydrate manipulation. European Journal of Applied Physiology, 112(8), 2859-2970.

Thomas, D. T., Erdman, K. A., \& Burke, L. M. (2016). Position of the Academy of Nutrition and Dietetics, Dietitians of Canada, and the American College of Sports Medicine: Nutrition and Athletic Performance. Journal of the Academy of Nutrition and Dietetics, 116(3), 501-528.

Welsh, R. S., Davis, J. M., Burke, J. R., \& Williams, H. G. (2002). Carbohydrates and physical/mental performance during intermittent exercise to fatigue. Medicine \& Science in Sports \& Exercise, 34(4), 723-31.

Williams, C., \& Rollo, I. (2015). Carbohydrate Nutrition and Team Sport Performance. Sports Medicine, 45(1), 13-22. 
"The Pre-Competition Macronutrient Intake of Elite Gaelic Football Players" by Cassidy C, Collins K, Shortall M International Journal of Sport Nutrition and Exercise Metabolism

(C) 2018 Human Kinetics, Inc.

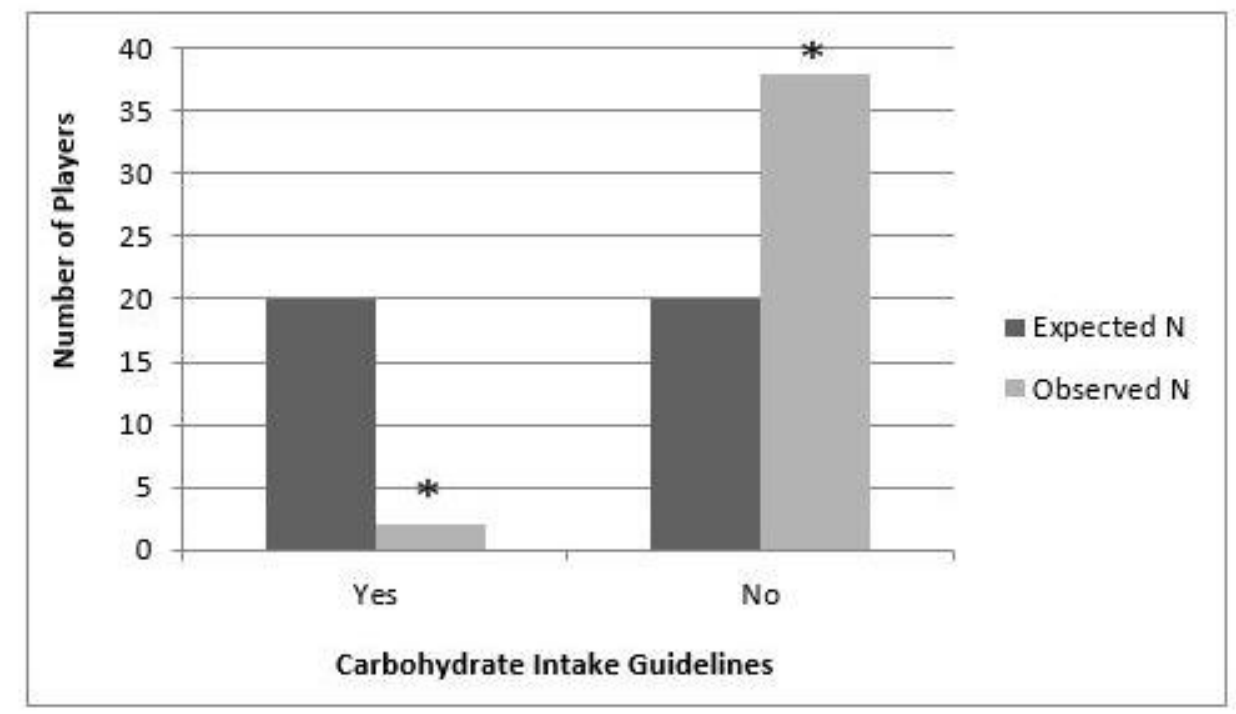

Figure 1: Number of players in accordance with the guidelines for relative carbohydrate intake $\left(7 \mathrm{~g} . \mathrm{kg}^{-}\right.$ ${ }^{1}$ ) on DAY-2. Yes $=$ in accordance with the guidelines; $\mathrm{No}=$ not in accordance with the guidelines [* = significantly different to an expected frequency distribution $(\mathrm{p}<0.05)]$. 
"The Pre-Competition Macronutrient Intake of Elite Gaelic Football Players" by Cassidy C, Collins K, Shortall M International Journal of Sport Nutrition and Exercise Metabolism

(C) 2018 Human Kinetics, Inc.

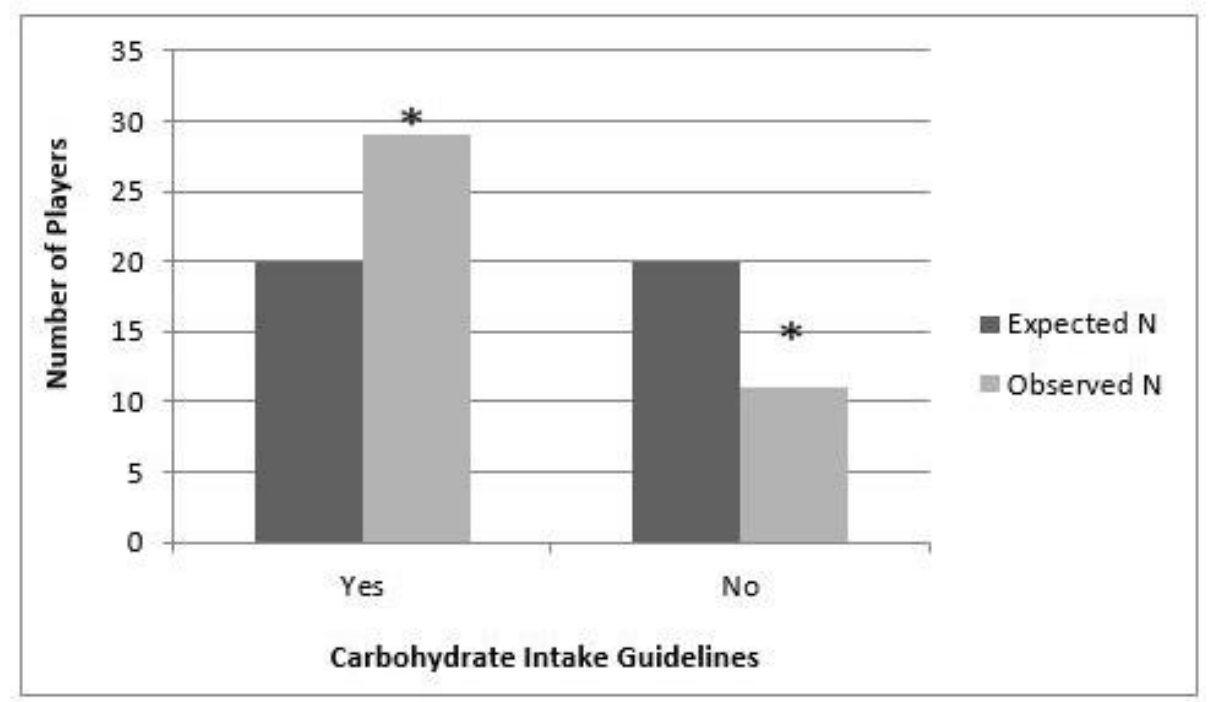

Figure 2: Number of players in accordance with the guidelines for relative carbohydrate intake (1-4 g. $\mathrm{kg}^{-1}, 1-4$ hours before) on MATCH-DAY. Yes $=$ in accordance with the guidelines; No $=$ not in accordance with the guidelines $[*=$ significantly different to an expected frequency distribution $(\mathrm{p}$ $<0.05)]$. 
"The Pre-Competition Macronutrient Intake of Elite Gaelic Football Players" by Cassidy C, Collins K, Shortall M International Journal of Sport Nutrition and Exercise Metabolism

(c) 2018 Human Kinetics, Inc.

Table 1: Energy and macronutrient intake (mean \pm SD) (*MATCH-DAY - pre-match: 10 a.m. -1 p.m.)

\begin{tabular}{|c|c|c|c|}
\hline & DAY-1 & DAY-2 & MATCH-DAY* \\
\hline Energy (kcal) & $2843 \pm 515$ & $2902 \pm 447$ & $900 \pm 325$ \\
\hline Energy (kcal.kg-1) & $33.5 \pm 6.3$ & $34.3 \pm 5.7$ & $10.7 \pm 3.9$ \\
\hline Carbohydrate (g) & $295 \pm 98$ & $318 \pm 77^{*}$ & $107 \pm 43$ \\
\hline Carbohydrate $\left(\mathrm{g} \cdot \mathrm{kg}^{-1}\right)$ & $3.4 \pm 1.1$ & $3.7 \pm 1.0^{*}$ & $1.3 \pm 0.5$ \\
\hline Carbohydrate (\% El) & $40.8 \pm 8.9$ & $45.6 \pm 8.8$ & $48.2 \pm 14.3$ \\
\hline Protein (g) & $170 \pm 32$ & $163 \pm 22$ & $49.7 \pm 26.3$ \\
\hline Protein (g.kg-1) & $2.1 \pm 0.4$ & $1.9 \pm 0.3$ & $0.6 \pm 0.3$ \\
\hline Protein (\% EI) & $24.3 \pm 4.2$ & $22.9 \pm 3.9$ & $22.1 \pm 8.7$ \\
\hline Fat (g) & $109 \pm 27$ & $101 \pm 28$ & $30.8 \pm 18.3$ \\
\hline Fat $\left(\mathrm{g} \cdot \mathrm{kg}^{-1}\right)$ & $1.3 \pm 0.3$ & $1.2 \pm 0.3$ & $0.3 \pm 0.2$ \\
\hline \multicolumn{4}{|c|}{$\left[^{*}=\right.$ significantly different to DAY-1 $\left.(p<0.05)\right]$} \\
\hline
\end{tabular}


"The Pre-Competition Macronutrient Intake of Elite Gaelic Football Players" by Cassidy C, Collins K, Shortall M International Journal of Sport Nutrition and Exercise Metabolism

(c) 2018 Human Kinetics, Inc.

Table 2: Guidelines for pre-competition carbohydrate intake

\begin{tabular}{lcc}
\hline \multicolumn{1}{c}{ Day } & Recommendation & Reference \\
\hline Day before competition & $7 \mathrm{~g} \cdot \mathrm{kg}^{-1}$ & (Burke et al., 2011) \\
Day of competition & $1-4{\mathrm{~g} \cdot \mathrm{kg}^{-1}(1-4 \mathrm{~h} \text { before) }}$ & (Thomas et al., 2016) \\
\hline
\end{tabular}

